\title{
Development of phytase-expressing chlamydomonas reinhardtii for monogastric animal nutrition
}

\author{
Fernanda Erpel ${ }^{\dagger}$, Franko Restovic ${ }^{\dagger}$ and Patricio Arce-Johnson ${ }^{*}$
}

\begin{abstract}
Background: In plant-derived animal feedstuffs, nearly $80 \%$ of the total phosphorus content is stored as phytate. However, phytate is poorly digested by monogastric animals such as poultry, swine and fish, as they lack the hydrolytic enzyme phytase; hence it is regarded as a nutritionally inactive compound from a phosphate bioavailability point of view. In addition, it also chelates important dietary minerals and essential amino acids. Therefore, dietary supplementation with bioavailable phosphate and exogenous phytases are required to achieve optimal animal growth. In order to simplify the obtaining and application processes, we developed a phytase expressing cell-wall deficient Chlamydomonas reinhardtii strain.

Results: In this work, we developed a transgenic microalgae expressing a fungal phytase to be used as a food supplement for monogastric animals. A codon optimized Aspergillus niger PhyA E228K phytase (mE228K) with improved performance at pH 3.5 was transformed into the plastid genome of Chlamydomonas reinhardtii in order to achieve optimal expression. We engineered a plastid-specific construction harboring the mE228K gene, which allowed us to obtain high expression level lines with measurable in vitro phytase activity. Both wild-type and cellwall deficient strains were selected, as the latter is a suitable model for animal digestion. The enzymatic activity of the $m E 228 \mathrm{~K}$ expressing lines were approximately 5 phytase units per gram of dry biomass at $\mathrm{pH} 3.5$ and $37^{\circ} \mathrm{C}$, similar to physiological conditions and economically competitive for use in commercial activities.

Conclusions: A reference basis for the future biotechnological application of microalgae is provided in this work. A cell-wall deficient transgenic microalgae with phytase activity at gastrointestinal pH and temperature and suitable for pellet formation was developed. Moreover, the associated microalgae biomass costs of this strain would be between US\$5 and US\$60 per ton of feedstuff, similar to the US\$2 per ton of feedstuffs of commercially available phytases. Our data provide evidence of phytate-hydrolyzing microalgae biomass for use as a food additive without the need for protein purification.
\end{abstract}

Keywords: Microalgae, Phytase, Animal nutrition

\section{Background}

Phytic acid (myo-inositol hexakisphosphate or IP6) is the major phosphate source in plant seeds, accounting for nearly $80 \%$ of the total phosphate content. It is mostly found as phytate, and forms metal complexes with divalent cations, such as $\mathrm{Ca}^{2+}, \mathrm{Mg}^{2+}, \mathrm{Zn}^{2+}$ and $\mathrm{Fe}^{2+}[1,2]$. Monogastric animals are incapable of digesting phytate from plant-derived feeds, due to the lack of a phytase

\footnotetext{
* Correspondence: parce@bio.puc.cl

${ }^{\dagger}$ Equal contributors

Departamento de Genética Molecular y Microbiología, Pontificia Universidad Católica de Chile, Alameda 340, Santiago, Chile
}

enzyme. Moreover, phytate exerts a strong chelating activity over positively-charged minerals and essential amino acids, reasons for which it is considered an important anti-nutrient $[3,4]$. Therefore, in order to sustain animal nutritional needs, the livestock industry uses exogenous inorganic phosphate, greatly increasing total costs. Regarding this, during the last decade, the price of phosphate has risen sharply from US $\$ 200 / t$ to US $\$ 1200 / t$, and is the third highest cost after energy and amino acids. From an ecological point of view, this agricultural practice is leading to an alarming increase in excreted phosphate levels and eutrophication of natural resources [5, 6]. Phytases 
(myo-inositol hexakisphosphate phosphohydrolases) on the other hand, are part of a phosphatase family that catalyzes the sequential dephosphorylation of phytate [7]. They are divided into two groups, according to phylogenetic analysis and biochemical properties: alkaline phytases, that have a strong preference for calcium-binding phytate; and the histidine acid phytases (HAP), which use mostly free phytate as substrate and show enzymatic activity at acid $\mathrm{pH}$ (between 2.5 and 6) and temperatures over $40{ }^{\circ} \mathrm{C}$ [8]. The application of phytases into the diet of monogastric animals has been adopted worldwide, not only with benefits for animal growth, but also for the environment. The use of HAPs has been directly correlated with a higher phosphate, mineral and essential amino acid bioavailability [3, 4]. Moreover, replacement of exogenous dicalcium phosphate by phytases, diminishes the phosphate concentration in swine excretions by 30-60 \% [9]. An ideal phytase model should 1) be able to effectively hydrolyze phytate in order to obtain sufficient inorganic phosphate to supply the animal requirements, 2) be able to resist high temperatures in order to be incorporated into food pellets, and 3) have low production costs. Kim, Mullaney [10] developed single and multiple mutants of the Aspergillus niger PHYA gene, resulting in a single mutant (E228K) with a shifted optimum pH (from 5.5 to 3.8) and $266 \%$ greater hydrolysis of phytate at $\mathrm{pH} 3.5$ compared to the wild-type version, the same $\mathrm{pH}$ as found in the gastrointestinal system of monogastric animals.

On the other hand, microalgae have generated an enormous industrial interest as model systems for the production of added-value molecules. Among these, Chlamydomonas reinhardtii is the most recognized microalgae due to its suitability for genetic transformation and scalability; moreover, various examples of recombinant protein expression are available [11-14]. Improved recombinant protein production has been achieved by targeting via homologous recombination, specific plastid regions in order to obtain high gene expression, bypassing the known nuclear gene silencing that affects this organism [11, 12]. Several mutant strains of $C$. reinhardtii are available, among them the cell-wall deficient strain $c w 15$, which is an excellent model for easily digestible microalgae [15]. Additionally, these organisms are an excellent source of carbohydrates, proteins and several nutrients, and have been accepted as Generally Recognized As Safe (GRAS), ensuring their use in the food and medical industries [16]. From an economic standpoint, microalgae are low cost production bio-factories; estimated costs based on antibody production in mammal, plant and microalgae systems are US\$150, US\$0.005 and US $\$ 0.002$, respectively [17]. Taken together, microalgae are thus excellent model organisms for use in animal feeds due to the ecological, economical and practical advantages. For these reasons, we expressed an optimized version of the PHYA E228K gene (hereafter named $m E 228 K)$ in both wild-type and cell-wall deficient $c w 15$ C. reinhardtii strains. Cell wall mutants could be useful in applications where cell disruption is needed, as for example, in animal nutrition. Phytase produced by microalgae effectively hydrolyzes phytate and should be able to resist high pelleting-like temperatures.

\section{Results \& discussion}

The potential of microalgae for producing high-value molecules, and their use in economically important activities as an oral administration vehicle have already been demonstrated [18]. C. reinhardtii has been extensively used as a model protein factory, and here we show how a cell-wall mutant ( $c w 15)$ could be used in the administration of phytase into animal feedstuffs. We chose an improved version of the PhyA gene of Aspergillus niger, with a higher activity at $\mathrm{pH} 3.5$, as found in the gastrointestinal system of monogastric animals [10].

\section{Codon optimization of the PHYA E228K gene}

We chose the PhyA E228K mutant, developed by Kim, Mullaney [10], as the phytase gene to express in C. reinhardtii. The wild-type version of PhyA has a double activity-peak $\mathrm{pH}$ profile, with two marked peaks at pH 2.5 and 5.5 [19]. However, the E228K mutant shifts the optimal $\mathrm{pH}$ to 3.8 and greatly increases phytate hydrolysis at $\mathrm{pH} 3.5$, which is the typical $\mathrm{pH}$ of the digestive tract of monogastric animals [10]. In order to obtain an increased expression in C. reinhardtii, we performed codon optimization of the E228K mutant nucleotide sequence. A C. reinhardtii codon usage table was obtained from Nakamura, Gojobori [20], and this information was used in the OPTIMIZER webpage, where the optimization of the desired sequence was undertaken [21, 22]. It is worth noting that only the mature protein sequence was used, devoid of the extracellular destination $\mathrm{N}$-terminal peptide, in order to trap the enzymatic activity within the intracellular space of the transformed microalgae. The resulting optimized gene $(m E 228 K)$ was synthesized and cloned into a SmaI-digested pBluescript II SK(-) derivative lacking its multiple cloning sites (EPOCH Life Science, http://www.epochlifescience.com/). Further analysis of the optimized gene showed that more than half of the codons were optimized (51.56\%), whereas the sequences have a $78.1 \%$ of nucleotide identity, and maintain $100 \%$ amino acid identity. The detailed sequence information is shown in Fig. 1.

\section{Determination of transformation pressures}

In order to optimize wild-type (UTEX-90) and $c w 15$ transformation, we subjected both strains to different 


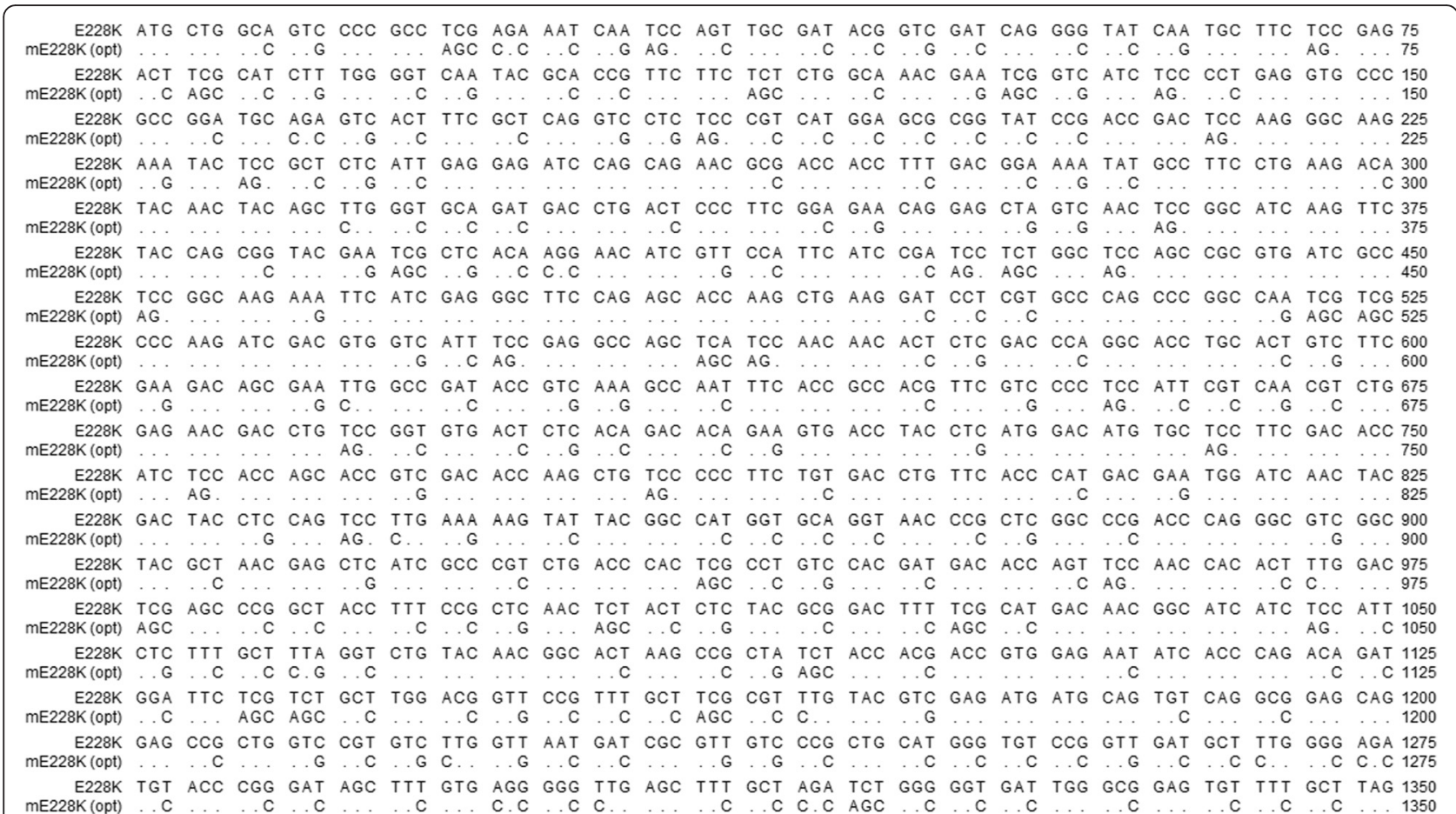

Fig. 1 Codon optimization of the E228K gene; Codon optimization of the E228K gene described in Kim, Mullaney [10], based on the Chlamydomonas reinhardtii codon database [20]

shooting pressures of between 250 and 600 psi with an empty p3HB-Kan vector. Kanamycin resistant colonies were counted after incubation for 7 days in the presence of the antibiotic. As expected, more UTEX-90 colonies appeared at higher pressures (between 400 and $600 \mathrm{psi}$ ), whereas the cell-wall deficient strain was more efficiently-transformed at a lower pressure (near 350 psi; Fig. 2). Following this result, we determined

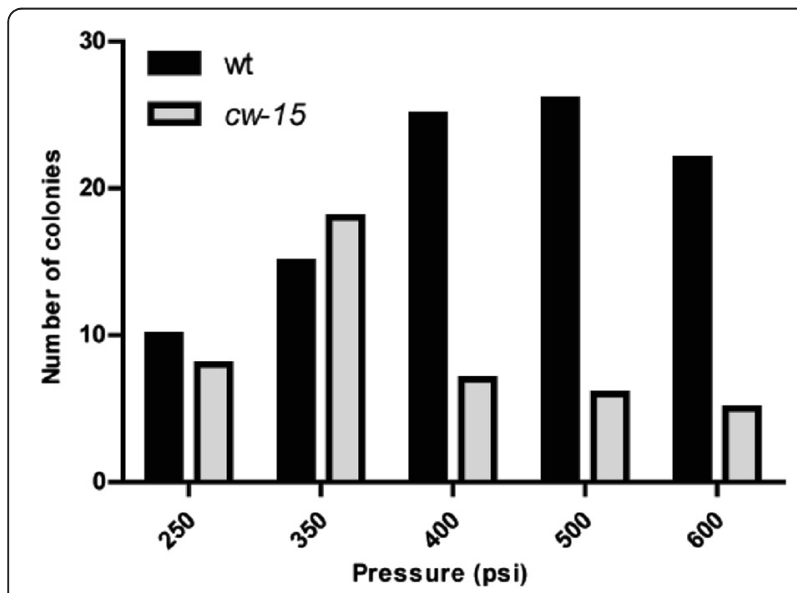

Fig. 2 Optimization of biolistic transformation pressures for UTEX-90 and cw15 strains; Total sum of kanamycin-resistant colonies from three transformation experiments for both UTEX-90 (black bars) and cw15 (grey bars) strains, using pressures ranging from 250 to 600 psi
500 and 350 psi as the optimal shooting pressures for UTEX-90 and $c w 15$ strains, respectively.

\section{Cloning into the p3HB-Kan vector and transformation of Chlamydomonas reinhardtii}

The synthesized gene $(m E 228 K)$ was cloned into the p3HB-Kan vector between the NdeI and XbaI sites [12]. The resulting vector ( $\mathrm{p} 3 \mathrm{HB}-\mathrm{Kan}-m E 228 K$ ) contains two regions of inverted repeats of the $C$. reinhardtii chloroplast genome (for homologous recombination) flanking a construction bearing the PSBD promoter/5'UTR, the optimized $m E 228 K$ gene and the PSBA 3'UTR region, in addition to the APHA6 gene flanked by the ATPA promoter $/ 5^{\prime} \mathrm{UTR}$ and the $R B C L 3$ 'UTR, for kanamycin resistance (Fig. 3a). In order to transform C. reinhardtii, the p3HB-Kan- $m E 228 K$ plasmid was coated onto nanogold particles, and then delivered into cells of UTEX-90 and $c w 15$ strains plated in TAP-Agar plaques using a biolistic approach with shooting pressures of 500 and $350 \mathrm{psi}$, respectively. After two weeks of incubation at $16 \mathrm{~h}$ light $/ 8 \mathrm{~h}$ dark and $24{ }^{\circ} \mathrm{C}$ in the presence of kanamycin, we obtained 65 resistant colonies, which were subsequently inoculated into $1 \mathrm{ml}$ of liquid TAP medium without antibiotics for recovery. From these colonies, 30 were classified as stable transformants as determined by amplification of a vector region comprising part of the 


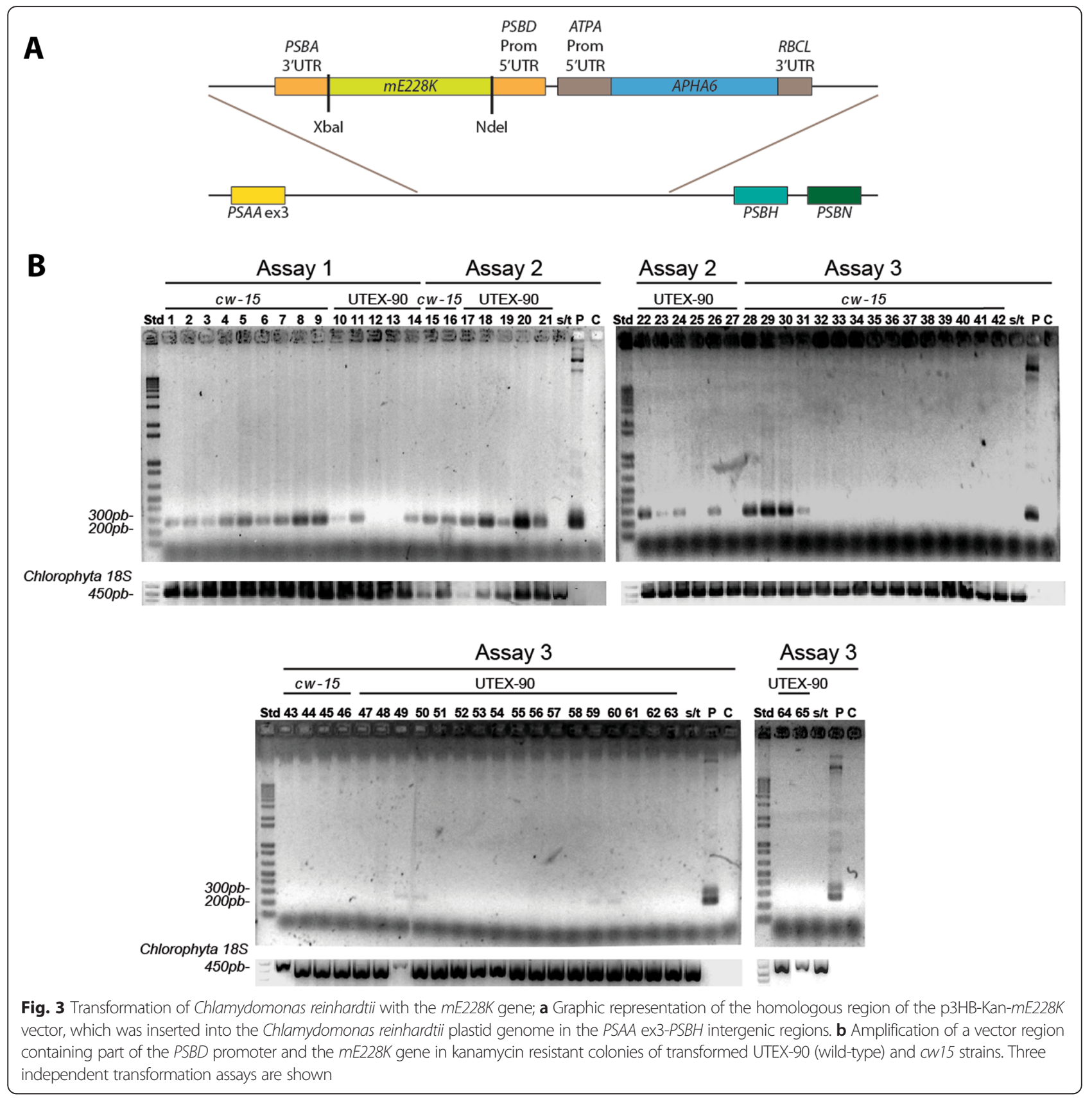

promoter and the $m E 228 K$ gene, and at least two further sub-cultures in selective media (Fig. 3b).

\section{Expression of the $m E 228 \mathrm{~K}$ transgene in transformed UTEX-90 and $c w 15$ strains}

To determine if kanamycin resistant colonies were expressing the $m E 228 K$ transcript, we selected the four best-growing UTEX-90 (L18, L19, L20 and L23) and cw15 (L2, L3, L5 and L31) transformed lines (data not shown) and analyzed them by RT-qPCR using $m E 228 K$ specific primers. All transformed lines expressed the phytase gene between 75 and 275-fold compared to non-transformed controls (Fig. 4).

\section{Phytase activity determination}

A functional in vitro assay was performed in order to assess the enzymatic activity of the transformed microalgae lines. This method consisted in the detection of the released inorganic phosphate from exogenous phytic acid, which is measured colorimetrically. The total absorbance detected at $400 \mathrm{~nm}$ is directly proportional to the liberated inorganic phosphate. The microalgae lines 


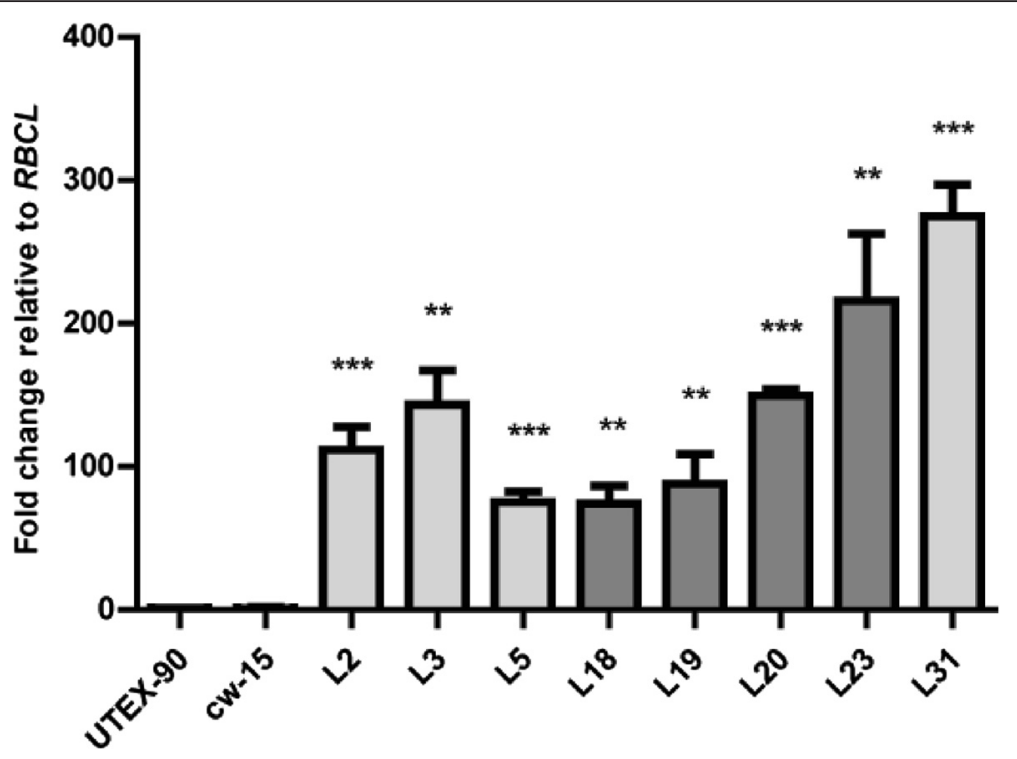

Phytase-expressing UTEX-90 and $c w-15$ lines

Fig. 4 Expression levels of phytase-expressing UTEX-90 and cW15 lines; RT-qPCR analysis of the mE228K transcript in transformed UTEX-90 (dark grey; control, L18, L19, L20 and L23) and cw15 (light grey; control, L2, L3, L5 and L31) lines. The mRNA levels are shown as fold-change relative to the internal control RBCL. Asterisks indicate significant differences ( $n=6 \pm \mathrm{SEM}^{* *}: 0.01>p>0.001 ;{ }^{* * *}: p<0.001$; all analysis compared to the non-transformed line)

with significant $m E 228 K$ expression were lyophilized, and the resulting dry biomass was resuspended with phytate and assayed for phytase activity for $30 \mathrm{~min}$ at $37^{\circ} \mathrm{C}$ at $\mathrm{pH}$ 3.5. We obtained three lines with significant phytase activity. Of these lines, two corresponded to cw15 lines (L5 and L31) and the remaining to a UTEX90 line (L23; Fig. 5).

Surprisingly, highest phytase activity (L5) did not correlate with higher gene expression, as transcript levels of L23 and L31 lines were approximately 2.8 and 3.6 fold higher than L5, respectively. Focusing on L5, the phytase activity of this line as determined at $37{ }^{\circ} \mathrm{C}$ and $\mathrm{pH} 3.5$, was 5 units per gram of lyophilisate ( $\mu$ mols of free phosphate per $30 \mathrm{~min} * 0.1 \mathrm{~mL}$ of homogenate * $50 \mathrm{mg}$ of lyophilisate dissolved in $1 \mathrm{~mL}$ of homogenate). Commercial product recommendations for phytase use in pig and chick feed are near 250-500 units per $\mathrm{kg}$ of feedstuffs (Natuphos; taking into consideration that commercial units are determined at $\mathrm{pH} 4.5$, and not 3.5 , the actual digestive system $\mathrm{pH}$ of monogastric animals). This means that $50-100 \mathrm{~g}$ of lyophilized microalgae would be sufficient for every $\mathrm{kg}$ of feedstuffs (without considering the additional nutrients that microalgae biomass possess). Considering the costs of microalgae biomass production, estimates indicate that they would range between $\$ 50$ and $\$ 600$ per ton, with conservative yields of at least $20 \mathrm{~g}$ dry weight $\mathrm{m}^{-2}$ day $^{-1}[18,23]$. Altogether, the associated microalgae biomass costs would be between US\$5 and US\$60 per ton of feedstuff, or even less at higher yields. These costs are relatively similar to the ones associated with phytase use in livestock feeding, which are near US\$2 per ton of feedstuff [6]. Furthermore, C. reinhardtii (and microalgae in general) has high nutritional value, with lipid, carbohydrates and total

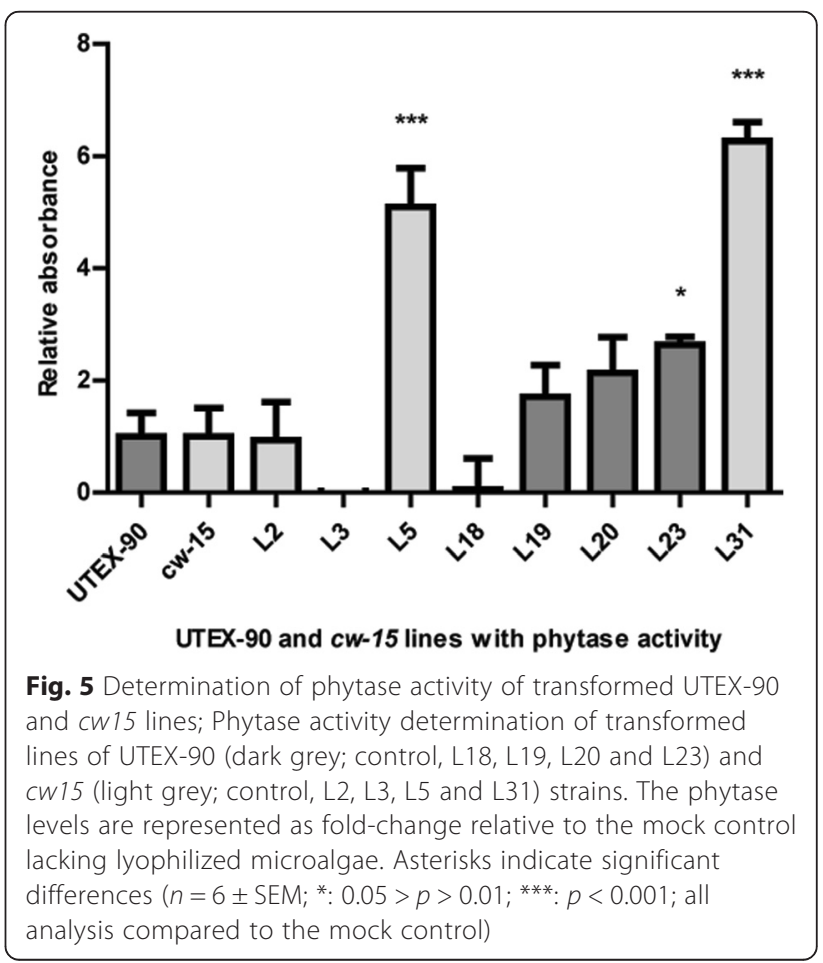


protein contents close to 21,17 and $48 \%$ of its dry weight, respectively [24], meaning that the inclusion of microalgae biomass in feedstuffs could reduce the need to supplement feeds with other amino acids and necessary nutrients. In addition, $C$. reinhardtii is classified as GRAS, making this organism a suitable model for protein expression and commercialization [25, 26]. The utilization of the cell wall deficient strain $c w 15$ should additionally provide a more suitable substrate for animal digestion, which could mean a higher phytase bioavailability in the gastrointestinal system, without the need for protein purification.

\section{Conclusions}

Phytase-expressing C. reinhardtii strains were developed to tackle the nutritional problems regarding phosphorus deficiency and general animal nutrition. The use of cellwall deficient strains should become a viable option for delivering specific enzymatic activities in animal nutrition. Animal experiments are needed to confirm the in vivo phytase activity and to assess the safety and nutritional benefits associated with microalgae consumption.

\section{Methods}

\section{Microalgae culture}

The Chlamydomonas reinhardtii UTEX-90 (wild-type) and $c w 15$ strains were obtained from the Microalgae Culture Laboratory from the Universidad de Concepción and the Chlamydomonas Resource Center (http:// www.chlamycollection.org/products/strains/), respectively. C. reinhardtii were grown in Tris-acetate-phosphate medium (TAP) at $25^{\circ} \mathrm{C}$, with a $16 \mathrm{~h}$ light $/ 8 \mathrm{~h}$ dark photoperiod in an orbital shaker at $180 \mathrm{rpm}$ with 1000 lux.

\section{Cloning and obtaining of transformed microalgae}

The p3HB-Kan vector was a kind gift of Dr. Beth Rasala and Dr. Stephen Mayfield [11, 12]. Codon optimization of the $E 228 \mathrm{~K}$ gene was performed using the C. reinhardtii codon database (http://www.kazusa.or.jp/codon/) described by Nakamura, Gojobori [20]. The resulting optimized PHYA gene ( $m E 228 K)$ was synthesized in the pBSK GS52811 vector containing an ampicillin resistance gene between the NdeI and $\mathrm{XbaI}$ restriction sites (Epoch Life Science). The $m E 228 K$ gene was digested and subsequently cloned into p3HB-Kan, harboring the NdeI and XbaI sites. After cloning into p3HB-Kan, the insertion was confirmed by DNA sequencing.

Microalgae transformation by biolistics was performed as described in Rasala, Muto [11]. Briefly, UTEX-90 and $c w 15$ strains were cultivated in liquid TAP medium until the exponential growth stage (approximately $10^{6}$ cells $/ \mathrm{mL}$; $\mathrm{DO}_{750}$ : 0.4). Later, cells were spun down, resuspended in TAP medium at a concentration of $10^{9}$ cells $/ \mathrm{mL}$, and $10 \mu \mathrm{L}$ aliquots were cultivated in TAP-agar plates with
$50 \mu \mathrm{g} / \mathrm{mL}$ kanamycin. Afterwards, plated cells were subjected to transformation using the Helios ${ }^{\circ}$ Gene Gun (Bio-Rad, CA) with shooting pressures between 250 and 600 psi. The p3HB-Kan- $m E 228 K$ vector was coated onto gold particles following manufacturer's instructions. After transformation, cells were incubated for 7-10 days until growth of kanamycin-resistant colonies. The resistant colonies were inoculated into $1 \mathrm{~mL}$ of liquid TAP medium without antibiotic for recovery. Stable transformants were determined by Taq polymerase (Invitrogen) amplification of a vector region comprising part of the promoter and the $m E 228 K$ gene (primers: $5^{\prime}$-TTGTTTTTTTATTTTG GAGATACACGCC-3' and 5' -TCCTCGATCAGGGCGC TGTA- $3^{\prime}$ ), and growth in at least two further sub-cultures in selective media.

\section{Transcript expression determination}

Real time quantitative PCR (RT-qPCR) was performed in order to determine $m E 228 \mathrm{~K}$ gene expression in transformed microalgae. Briefly, microalgae were homogenized in a Precellys ${ }^{\circ} 24$ (Berlin Technologies) and RNA was obtained using the TRIzol ${ }^{\circ}$ reagent (Invitrogen). Then, $2 \mu \mathrm{g}$ of RNA were treated with the Turbo DNA-Free ${ }^{\mathrm{tm}}$ kit $\left(\right.$ Ambion $\left.^{\circ}\right)$ and cDNA was made with random primers and Superscript II ${ }^{\circ}$ Reverse Transcriptase (Invitrogen) following the manufacturer's protocol. Quantification of the $m E 228 K$ transcripts was performed using the Mx3000 $\mathrm{p}^{\mathrm{tm}}$ (Stratagene ${ }^{\circ}$ ) thermocycler and the SensiMix ${ }^{\text {tm }}$ Plus SYBR kit (Quantace) following manufacturer's procedure. The $R B C L$ gene was used as an expression normalizer, as described in Rasala, Muto [12]. Primers used were as follow: 5'-CCTGCAGAGCCTGAAGAAGT-3' and 5'CGAACAGGATGCTGATGATG-3' for $m E 228 K$; $5^{\prime}$ CAGTTGCTTCAGGCGGTATT-3' and ' 5'-AATTACG TCGCCACCTTCAC-3' for RBCL.

\section{Phytase activity assay}

Wild-type and phytase expressing cells were grown in $400 \mathrm{~mL}$ of selective media until the exponential growth phase (approximately $10^{6}$ cells). Cultures were centrifuged, washed with $1 \%$ glycerol and centrifuged again. The resulting pellets were frozen with liquid nitrogen, thawed and frozen again previous to lyophilization in a Freezone 2.5 Benchtop Liter Lyophilizer (Labconco). The lyophilized whole-cell lysates (dry microalgae biomass) were used for phytase activity assays.

Phytase activity quantification was performed as described by Heinonen and Lahti [27] with modifications. Briefly, $25 \mathrm{mg}$ of lyophilized microalgae were dissolved in $500 \mu \mathrm{L}$ of $200 \mathrm{mM} \mathrm{pH} 3.5$ sodium acetate - acetic acid buffer. In order to start the catalytic reaction, $100 \mu \mathrm{L}$ of each sample were added to $500 \mu \mathrm{L}$ of a $44.1 \mathrm{mM}$ sodium phytate solution (in acetate buffer) previously incubated at $37{ }^{\circ} \mathrm{C}$ for $5 \mathrm{~min}$. The mock was performed under the same 
conditions without the lyophilized microalgae, and a positive control was carried out adding $100 \mu \mathrm{L}$ of a commercial phytase solution (Natuphos ${ }^{\circ}$ ). After incubation for $30 \mathrm{~min}$ at $37{ }^{\circ} \mathrm{C}, 4 \mathrm{~mL}$ of CRS colorimetric solution (acetone, $5 \mathrm{~N}$ sulphuric acid and $5 \%$ ammonium molybdate; $2: 1: 1 \mathrm{v} / \mathrm{v} / \mathrm{v}$ ) was added, and absorbance $(400 \mathrm{~nm})$ was measured. A standard curve of absorbance was made with phosphate $(0.5-2.5 \mu \mathrm{mol}$ ). The enzymatic activity (units per $\mathrm{mg}$ of lyophilisate) was obtained as the $\mu$ mols of released phosphate per duration of assay, volume and lyophilisate mass.

\section{Availability of data and materials}

The dataset supporting the conclusions of this article is available in the GenBank (National Center for Biotechnology Information) repository KT899873.

\section{Competing interests}

The authors declare that they have no competing interests.

\section{Authors' contributions}

FE and FR contributed to the conception of the study. FE carried out the cloning and obtained the transformed microalgae. FE and FR did the phytase assays of transformed lines. FR drafted the manuscript. FE and PAJ were involved in revising the manuscript critically for important intellectual content. PAJ gave final approval of the version to be published. All authors read and approved the final manuscript.

\section{Acknowledgements}

This work was supported by CORFO-INNOVA 09CTEI6861-02. We thank Dr. Michael Handford, Universidad de Chile, for proof-reading the manuscript.

Received: 25 June 2015 Accepted: 7 March 2016

Published online: 12 March 2016

\section{References}

1. Reddy NR, Sathe SK, Salunkhe DK. Phytates in legumes and cereals. Adv Food Res. 1982;28:1-92. Epub 1982/01/01.

2. Urbano G, Lopez-Jurado M, Aranda P, Vidal-Valverde C, Tenorio E, Porres J. The role of phytic acid in legumes: antinutrient or beneficial function? J Physiol Biochem. 2000;56(3):283-94. Epub 2001/02/24.

3. Rao DE, Rao KV, Reddy TP, Reddy VD. Molecular characterization, physicochemical properties, known and potential applications of phytases: An overview. Crit Rev Biotechnol. 2009;29(2):182-98. Epub 2009/06/12.

4. Kumar V, Sinha A, Makkar H, Becker K. Dietary roles of phytate and phytase in human nutrition: a review. Food Chem. 2010;120:945-59.

5. Vats P, Banerjee UC. Biochemical characterisation of extracellular phytase (myo-inositol hexakisphosphate phosphohydrolase) from a hyper-producing strain of Aspergillus niger van Teighem. J Ind Microbiol Biotechnol. 2005; 32(4):141-7. Epub 2005/03/19.

6. Lei X, Weaver J, Mullaney E, Ullah A, Azain M. Phytase, a new life for an "Old" enzyme. Annu Rev Anim Biosci. 2013;1:283-309.

7. Wyss M, Brugger R, Kronenberger A, Remy R, Fimbel R, Oesterhelt G, et al. Biochemical characterization of fungal phytases (myo-inositol hexakisphosphate phosphohydrolases): catalytic properties. Appl Environ Microbiol. 1999;65(2):367-73. Epub 1999/01/30.

8. Oh BC, Choi WC, Park S, Kim YO, Oh TK. Biochemical properties and substrate specificities of alkaline and histidine acid phytases. Appl Microbiol Biotechnol. 2004;63(4):362-72. Epub 2003/10/31.

9. NRC. Nutrient Requirements of Swine: 10th Revised Edition. Washington, DC: The National Academies Press; 1998. p. 212.

10. Kim T, Mullaney EJ, Porres JM, Roneker KR, Crowe S, Rice S, et al. Shifting the $\mathrm{pH}$ profile of Aspergillus niger PhyA phytase to match the stomach $\mathrm{pH}$ enhances its effectiveness as an animal feed additive. Appl Environ Microbiol. 2006;72(6):4397-403. Epub 2006/06/06.

11. Rasala BA, Muto M, Lee PA, Jager M, Cardoso RM, Behnke CA, et al. Production of therapeutic proteins in algae, analysis of expression of seven human proteins in the chloroplast of Chlamydomonas reinhardtii. Plant Biotechnol J. 2010;8(6):719-33. Epub 2010/03/17.

12. Rasala BA, Muto M, Sullivan J, Mayfield SP. Improved heterologous protein expression in the chloroplast of Chlamydomonas reinhardtii through promoter and 5' untranslated region optimization. Plant Biotechnol J. 2011; 9(6):674-83. Epub 2011/05/04.

13. Tran M, Zhou B, Pettersson PL, Gonzalez MJ, Mayfield SP. Synthesis and assembly of a full-length human monoclonal antibody in algal chloroplasts. Biotechnol Bioeng. 2009;104(4):663-73. Epub 2009/06/30.

14. Wang X, Brandsma M, Tremblay R, Maxwell D, Jevnikar AM, Huner N, et al. A novel expression platform for the production of diabetes-associated autoantigen human glutamic acid decarboxylase (hGAD65). BMC Biotechnol. 2008;8:87. Epub 2008/11/19.

15. Wang ZT, Ullrich N, Joo S, Waffenschmidt S, Goodenough U. Algal lipid bodies: stress induction, purification, and biochemical characterization in wild-type and starchless Chlamydomonas reinhardtii. Eukaryot Cell. 2009; 8(12):1856-68. Epub 2009/11/03.

16. Gantar M, Svircev Z. Microalgae and cyanobacteria: food for thought. J Phycol. 2008;44:260-8.

17. Mayfield SP, Franklin SE, Lerner RA. Expression and assembly of a fully active antibody in algae. Proc Natl Acad Sci U S A. 2003;100(2):438-42. Epub 2003/01/11

18. Specht E, Miyake-Stoner S, Mayfield S. Micro-algae come of age as a platform for recombinant protein production. Biotechnol Lett. 2010;32(10): 1373-83. Epub 2010/06/18.

19. Ullah AH, Gibson DM. Extracellular phytase (E.C. 3.1.3.8) from Aspergillus ficuum NRRL 3135: purification and characterization. Prep Biochem. 1987; 17(1):63-91. Epub 1987/01/01.

20. Nakamura Y, Gojobori T, Ikemura T. Codon usage tabulated from international DNA sequence databases: status for the year 2000. Nucleic Acids Res. 2000;28(1):292. Epub 1999/12/11

21. Puigbo P, Romeu A, Garcia-Vallve S. HEG-DB: a database of predicted highly expressed genes in prokaryotic complete genomes under translational selection. Nucleic Acids Res. 2008;36(Database issue):D524-7. Epub 2007/10/16.

22. Puigbo P, Guzman E, Romeu A, Garcia-Vallve S. OPTIMIZER: a web server for optimizing the codon usage of DNA sequences. Nucleic Acids Res. 2007; 35(Web Server issue):W126-31. Epub 2007/04/19.

23. Williams PJB, Laurens LML. Microalgae as biodiesel \& biomass feedstocks: review \& analysis of the biochemistry, energetics \& economics. Energy Environ Sci. 2010;3:554-90.

24. Becker EW. Micro-algae as a source of protein. Biotechnol Adv. 2007;25(2): 207-10. Epub 2007/01/02.

25. Mayfield SP, Franklin SE. Expression of human antibodies in eukaryotic micro-algae. Vaccine. 2005;23(15):1828-32. Epub 2005/03/01.

26. Mayfield SP, Manuell AL, Chen S, Wu J, Tran M, Siefker D, et al. Chlamydomonas reinhardtii chloroplasts as protein factories. Curr Opin Biotechnol. 2007;18(2):126-33. Epub 2007/02/24.

27. Heinonen JK, Lahti RJ. A new and convenient colorimetric determination of inorganic orthophosphate and its application to the assay of inorganic pyrophosphatase. Anal Biochem. 1981;113(2):313-7. Epub 1981/05/15.

Submit your next manuscript to BioMed Central and we will help you at every step:

- We accept pre-submission inquiries

- Our selector tool helps you to find the most relevant journal

- We provide round the clock customer support

- Convenient online submission

- Thorough peer review

- Inclusion in PubMed and all major indexing services

- Maximum visibility for your research

Submit your manuscript at www.biomedcentral.com/submit 